\title{
FIRE AND SPRUCE
}

BY W. J. BLOOMBERG

\section{Alberta Forest Service, Edmonton, Alberta}

Cruising in the eastern slope forests of the southern Canadian Rockies last summer one could not help but be impressed by the great age and stability of these spruce-fir stands. More remarkable was the absence of any preparation on the part of these apparently climactic types to perpetuate themselves. Spruce regeneration was conspicuous by its scarcity and fir, though proportionately greater than the final stand composition would warrant, was hardly profuse enough to fill in sparse spots and gaps.

Granted that the development of such stands extends over a 350-year rotation it might seem like super-optimism to expect complete restocking at a mere 150-200 years. In actual fact regeneration has already hit its high and will decline steadily in quantity and vigor at any age from 100 years up. Since the parent stand itself has hardly emerged from adolescence at that age each succeeding year would appear to bring it closer toward extinction.

Analysis of the root-cause of the condition-isolating the inhibiting agency in the case of failure to regenerate and discovering how the climatic type survives despite its own suicidal tendency-was one of the objects of the study carried out and which is summarised in this paper.

The 90 square mile area investigated centres around a minor tributary of the Oldman River in the Blairmore District of Southwestern Alberta. Westerly it stretches to the Divide and apart from being somewhat more abrupt is typical of the eastern slope forests in Alberta. It is an area of high lightning risk. The mature timber consists solely of a spruce-balsam fir association running from $8-35 \mathrm{M}$ ft. b.m. per acre and generally well-stocked. Lodgepole pine regenerated thickly on burns, stagnated at 150 years and was gradually succeeded by spruce.

In appearance the spruce stands resembled a typical all-aged haphazard natural selection forest. It was only in the analysis of age-counts and the abortive attempt to construct an age-diameter curve that it became very clear that the age-class distribution was irregular-to say the least.

Actual age-class distribution over the whole area was as follows:

$\begin{array}{ccc} & \text { Age Class } & \text { Percentage of whole } \\ 1 & (0-50 \text { years }) & \text { Nil } \\ 2 & (51-100 \text { " }) & \text { Nil } \\ 3 & (101-150 \text { " }) & 1 \% \\ 4 & (151-200 \text { ", }) & 12 \% \\ 5 & (201-250 \text { ", }) & 57 \% \\ 6 & (251-300 \text { ", } & 25 \% \\ 7 & (301-500 \text { ") }\end{array}$

The lack of treees is classes 1 and 2 immediately prompted an investigation of the smaller diameter classes. No exception occurred-these stems

1. The material used in this paper was drawn from a departmental report submitted to the Director of Forestry, Alberta, and is reprinted in part with his permission. 
were merely sickly individuals which had lost the race in suppression. A few examples are given below.

$\begin{array}{lr}D B H & \text { Age } \\ 3.1 & 100 \\ 5.8 & 120 \\ 6.3 & 150\end{array}$

Since 82 per cent of the trees are in classes 5 and 6 it can be argued that the whole area was regenerated as a result of some cataclysmic phenomenon immediately preceding that 100 year period. The one that springs most obviously to mind is fire.

Subsequent scedings from the established stand will account for the 13 per cent in classes 3 and 4 while it is reasonable to assume that 5 per cent of the stand managed to survive the destruction.

This, then, is a condition falling partway between an even-aged and an irregular forest. It is even-aged to the extent that 80 per cent of the stand was established during the regeneration period and irregular in that the balance was supplied by re-seeding within the established stand until some agency precluded regeneration.

The examination of a stand in the transition period during which fireestablished pine is being overtaken and succeeded by spruce gave a clue to the events of the natural succession cycle leading to the establishment of a climactic spruce-fir stand.

The pine content of this stand consisted of vigorous young trees whose ages deviated little from 75 years and clearly constituted from 6"-13" DBH. Below the pine a fairly dense story of young spruce was well established. Two distinct age classes showed up here, one of 48 and the other of 65 years. The diameter range in both classes was from $3^{\prime \prime}-12^{\prime \prime} \mathrm{DBH}$. Furthermore, the trees in the older age class were poorly developed and all showed incipient or actual butt-rot, whereas the younger stems were clean and vigorous.

In addition to the three predominant age classes, large mature spruce trees up to $30^{\prime \prime} \mathrm{DBH}$ and about 200 years old were scattered throughout the stand. There were about 20 of these to the acre. Finally, badly-decayed butts just recognizable as spruce were present in a half-buried condition. This was the time-picture from which the history of the stand was reconstructed.

Suppose a mature or over-mature spruce stand is subjected to a highly destructive fire. A few individuals may escape. These would be vigorous middle-aged trees says 100 years old, since young trees would perish from scorch and the older trees would almost certainly suffer windfall as a result of the drastic thinning.

As a result of the fire a dense young pine stand is established providing the shade and stabilizing effect necessary to rebuild the site. This pioneer phase may extend to the tenth year after the fire, longer in some cases depending largely on microclimatic conditions.

The rehabilitative spadework carried out by the young pine stand now results in a receptive site for the successful regeneration of spruce and an 
exceptionally good year will bring in a crop of young plants thriving on the fire-disturbed soil plus the shade and leaf litter provided by the pine stand. The spruce is established in a comparatively short period but is not very dense owing to the limited number of seed trees.

Spruce seeding will, of course, continue; but such has been the precarious condition of the site that it requires optimum conditions to establish a crop. This does not occur until 16 or 17 years later when a cousin generation of spruce establishes itself in the stand openings not previously stocked. At this stage, however, the soil and environmental conditions are much more favourable to spruce, the original site having been ameliorated by the first spruce generation, particularly in the matter of increased shade and ground cover; consequently growth is more vigorous, cull is absent and increment high. The following figures illustrate this.

\begin{tabular}{lccc}
\multicolumn{1}{c}{ Crop } & Age & Increment & Vigor \\
1st generation spruce & 210 years & $\frac{.32 \mathrm{in.}}{\text { Good }}$ & High \\
1st generation pine & 70 "n & $.58 \mathrm{in}$. & Hen \\
2nd generation spruce & $65 "$ & $.20 \mathrm{in.}$ & Poor \\
1st seeding & $48 "$ & $.50 \mathrm{in}$. & High \\
2nd seeding & &
\end{tabular}

It would seem that this point marks the climax in the evolution of a good spruce site. Degeneration of the site as the spruce content increases and matures is accompanied by fir invasion and diminishing spruce regeneration. It is significant that fir was entirely absent in the initial stages of the conditions under study. Pine regeneration was rare throughout the area indicating a single pioneer generation in this species.

A tally of similar-sized spruce trees under a mature spruce canopy provided some comparison of tree vigor at both extremes of the cycle, increment in the table below being comparable with that in the table above.

\begin{tabular}{rl}
$\frac{\text { Age }}{80}$ & Increment \\
120 & .055 in. \\
150 & .055 in. \\
210 & .052 in. \\
\hline
\end{tabular}

It is seen from the above analysis that the reseeding of the area with spruce depends on the escape of a few trees in the original spruce stand. In a highly destructive fire it is possible that no trees would survive. Here an examination of the first phase of the cycle, i.e. a restocking burn, threw some light on spruce regeneration. This area was burned in 1936 and, since a large number of fire-killed stems were still standing, it was possible to classify the original stand as a mature spruce type, probably running $15 \mathrm{M}$ ft.b.m. to the acre. Destruction in this case was 100 per cent. Restocking was rapid, and dense young pine now covers the area. Scattered among the pine, spruce seedlings were present to an estimated extent of 1000 per acre in some places and non-existent in others.

Again fir regeneration was entirely absent. Examination showed that the density of the spruce seedlings was proportional to (1) the density of 
the young pine; (2) the seeding distance from the mature marginal spruce stands which had been left intact. This seldom exceeded $300 \mathrm{ft}$.

It has been stated previously that some agency within the mature spruce stand precluded regeneration after a certain period, in most cases 100-150 years after stand establishment. Comparison of a pine stand such as the case in point and a mature spruce stand immediately reveals two obvious differences. A great quantity of light penetrates the pine canopy and the ground under a pine canopy is clean of thick duff and trash, whereas in spruce the reverse is the case.

As the pure spruce stand establishes denser growth on the site, so these conditions are exacerbated to the point where insufficient light and heat can penetrate the canopy to aid the decomposition of vegetable matter on the forest floor.

After the establishment of such a stand, reseeding from the mature trees results in a diminishing degree of successful regeneration as the stand closes and the severity of these conditions increases. The thickening humus layer prevents the delicate seedling rootlet from penetrating the mineral soil from which it will draw sustenance after the seed reserves are exhausted. The root and light competition prevents proper crown development, and the young tree becomes sickly and a prey to insect and fungal attack. When these conditions are further enhanced even successful germination is prevented. Balsam fir, however, being more tolerant and possessing a deeper tap root, will survive until it comprises almost 100 per cent of the successful regeneration.

At the extreme of this development the forest floor is strewn with windfall and other undecomposed vegetable refuse and a high fire hazard is constituted. Incidental lightning strikes no longer cause spot burns but will, during an exceptionally dry season, explode into a major conflagration, resulting in 100 per cent destruction. This marks the end of one cycle and with the establishment of young pine, the beginning of another. Significantly, a pure fir overstory which would seem to be the logical climax of two consecutive fire free rotations, was not found in any part of the 90 square mile area. In other words the present rotation at least was inaugurated by fire. Assuming the premise that this type of spruce-fir complex is climactic on the Eastern Slopes then it follows that fire is not only associated with the succession cycle leading to the establishment of such a complex but is actually the kingpin of the whole structure; that without fire in such proportions as to be regarded as catastrophic from a protection point of view there would be no valuable forests to protect.

That spruce will grow to 500 years of age was proven by the significant number of trees bored and found to be in this age class. There would appear to be no reason why spruce trees generally should not attain this age unless interrupted by such destruction as fire would bring. The deterioration of site which must accompany the prolongation of such conditions as seen to be prejudicial to regeneration for another half rotation might conceivably jeopardize the chances of establishing a new crop whether by fire or any other means. It is, therefore, arguable that the natural life of the stand has been 
cut short with an object-that of ensuring the perpetuation of the species. The method in Nature's madness is, in this case, difficult to dispute.

Summarizing so far, we have seen that spruce regeneration is healthy and vigorous under a pine nurse crop, yet decadent or non-existent under a canopy of its own species; that a regular succession of age classes, the classically supposed ideal for spruce is mythical in the case we are considering; that the age-class distribution is directly attributable to fire. Further we are led to suppose that fire has a positive and causative effect on the establishment of spruce as a climax type. It would be well to stress that these principles were found to apply irrespective of site or other growth factors, and in the writer's range of experience and observation are widely prevalent on the Eastern Slopes.

This will immediately beg the question "What will be the state of affairs when the ideal of complete fire protection is realized?" This is pertinent in view of the rapid strides being made by the Alberta Government in this direction. Will it be found that without the revitalizing effect of fire on the soil we have merely succeeded in pampering unwanted scrub species to the exclusion of spruce, or that the forest floor will become so cluttered with masses of stagnated vegetable growth that eventually an elaborate and costly fire protection system will be protecting nothing more valuable than large areas of-to use an earthy cruising term-"crap?"

In Alberta, at least, forest fire is such a constant bed-fellow that there is no precedent to show what may happen when virgin stands are protected from fire for more than one rotation. It may not be too fantastic to consider the day when we shall wonder whether fire, in some form at least, has not been a friend masquerading as a foe. 